\title{
Supply chain management with a strategic modelling and simulation tool for virtual supplies
}

\author{
H. Laurikkala ${ }^{1)}$, E. Pajarre ${ }^{2)}$ \\ Tampere University of Technology, P.O. Box 541, 33101 \\ Tampere, Finland \\ 1) Tel: +35833653665 \\ Fax: +3583652027 \\ e-mail: helil@butler.cc.tut.fi \\ 2) Tel: +35833652545 \\ Fax: +3583652027 \\ e-mail:eilap@butler.cc.tut.fi
}

\begin{abstract}
The goal of the paper is to find modern means of information technology to support project oriented and networked companies in their supply chain management. Simo-2, a software for distributed business modelling and simulation, is introduced and the advantages gained by using it in preliminary project planning and management are described.
\end{abstract}

\section{Keywords}

Supply chain management, simulation, modelling, virtual enterprise. 
The aim of the paper is to find means of information technology to support project oriented and networked companies in their supply chain management. The paper introduces Simo-2 software, a distributed business simulation environment for virtual deliveries. The focus is on the modelling part because modularised modelling of product structure, business practices and project planning create a basis for successful simulation.

There are various specialised tools for product modelling, logistics, costs analysis and virtual teamwork etc. European MUSSELS project (Mussels, 1998) focuses on production oriented industry. Virtual Design Team, VDT (Jin et al, 1995) developed at the Stanford University concentrates on the simulation of group dynamics of a design team in concurrent engineering environment. PROVE (Rose, 1998 ) is a system helping to draft and outline work processes from the worker's point of view. There are also commercial systems like PlantSpace of Jacobus Technology Inc. (Jacobus, 1998) which concentrate on design support and project visualisation, as well as systems for logistics simulation. For document handling and support for cooperative work in distributed environment there are systems like BSCW, Basic Support for Cooperative Work (BSCW, 1998).

Though, these systems do not serve the needs of project oriented companies working in a networked environment. These companies need a system that supports different project planning and management needs as well as project follow-up. Prosit 9 project was launched in 1996 with the mission of building a strategic tool called Simo-2 for virtual deliveries of power plant producers. The project is carried out at Tampere University of Technology by the Institutes of Industrial Management and Machine Design, in close cooperation with industrial participants.

\section{SIMO-2 SOFTWARE}

\subsection{General}

Simo-2 tool provides means to model cooperation of enterprises with different goals and strategies. Simo-2 software is a distributed business simulation environment with a product model based approach for project deliveries. It provides a unified and a concrete representation of the intended project structure. Although Simo-2 is developed for power plant industry, the same system can be extended to cover all kinds of large one-of-a-kind delivery projects.

Simo-2 supports various project planning and management needs:

- Company-wise product, business and project modelling

- Defining consortium members' responsibilities and scopes of deliveries

- Contracting

- Scheduling 
- Resources

- Analysis of costs, resource usage, cash flow and duration of activities

\subsection{Architecture}

Simo-2 consists of a modelling tool, a distributed, multi-user project planning and simulation package, and a separate analysis tool. (Figure 1) The product and business modelling tool is a highly graphical set of methods built on top of the modelling software called MetaEdit + . Completed product and business models are transferred in HTML format from MetaEdit + to project modelling and simulation software where the data is inserted in an internal object-oriented database. The database is an integral part of the tool and does not need separate administration. Both the simulation tool and its WWW browser based user interface are written in Java to allow the best possible transferability.

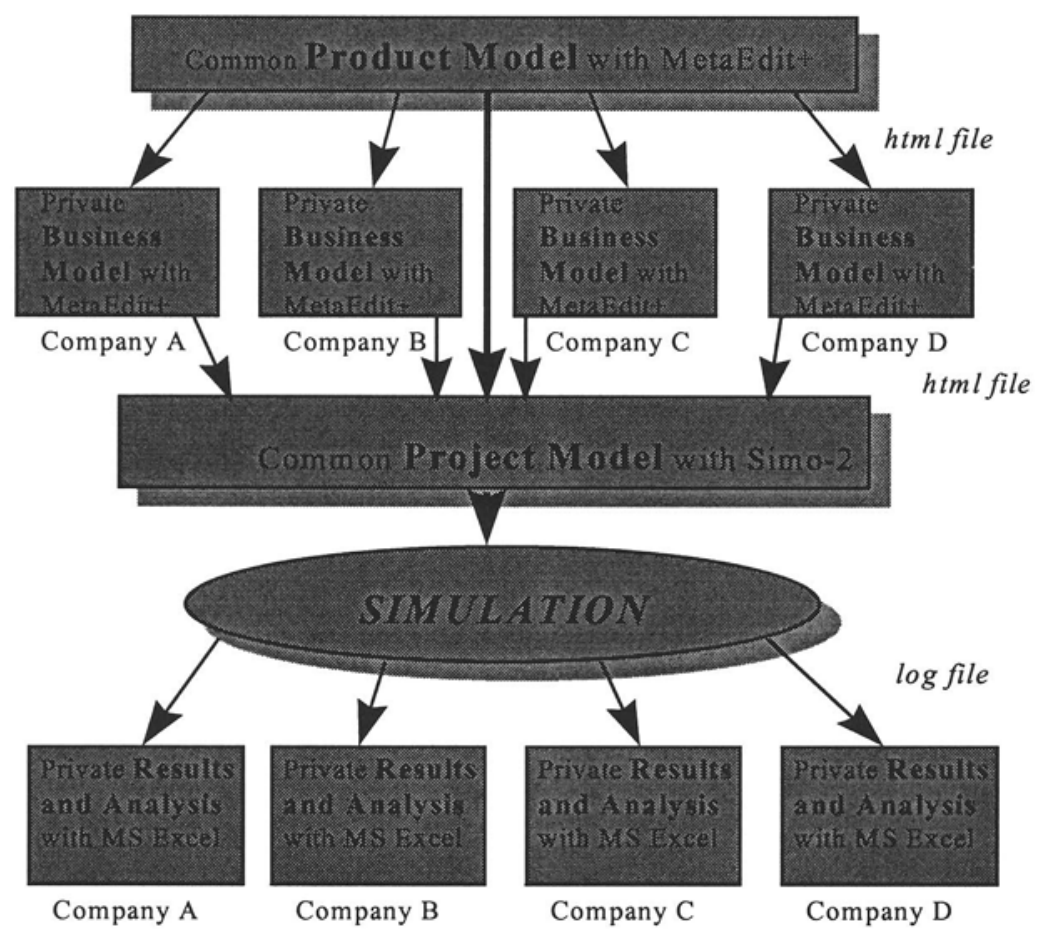

Figure 1 Architecture of Simo-2 software.

Dividing modelling into three phases - product, business, and project modelling has several advantages:

- Three levels of model dynamics are reached automatically. 
- A product model is a base for business modelling and product and business models together are a static base for project modelling.

- Security aspects are easier to handle.

- It is possible to choose the best possible tools for each phase.

Simo-2 servers are designed to work interactively so that each company has its own server containing its own private business model and a copy of the common product model in use. Communication between different servers, as well as between one server and its user interface, is implemented using secured CORBA connections. Simulation is distributed so that only public results of the simulation are shared between the participants.

The information coming from Simo-2 log file (i.e. costs, resources used, cash flow, duration of operations etc.) is read to MS Excel and transferred to the format suitable for each company. Therefore the companies can use the tool for comparing plans to simulated results or even to real project information and the most important of all, use their own key figures.

\section{MODELING}

\subsection{Practices}

Almost all the projects suffer from the lack of systematic project follow-up. Projects are seen as unique, which results in a misconception that they are unnecessary to follow-up, that learning from them is impossible and that they simply can not be modelled. This is not the case. Even though duration, configuration and location of a power plant may vary to a great deal from project to project, there are still many aspects that are in common. These include e.g. product structure (main components and parts), contract forming, standard subcontractors and service providers (logistics companies etc.), terms of delivery, strategies according to market segments and cooperation between companies. (Laurikkala, 1998)

When modelling business practices of each company, somebody inside the company should be highly involved in the project. The first models were created mostly by the project group, after which the contact persons gave their comments and suggestions. The first models could not model the business practices well enough, their aim was just to get acquainted with the ways of modelling and to become familiar with the modelling tool. At the first phase, this was challenging enough and took for several months.

The information for modelling has to be collected from several sources in order to get a proper perspective to business practices. This meant several interviews with several interviewees. Also, the depth and the accuracy of the model had to be decided. (Laurikkala et al., 1999)

At the first phase of the project, the following information was gathered:

- The scope of a firm (i.e. what it designs, produces, sells etc.)?

- How to design, order, purchase, manufacture, pack, transport, warehouse, ship and assemble the parts the firm is responsible for? 
- What resources are needed?

- How long does it take and how much does it cost?

The information attained was divided into product and business models as shown in Figure 2.

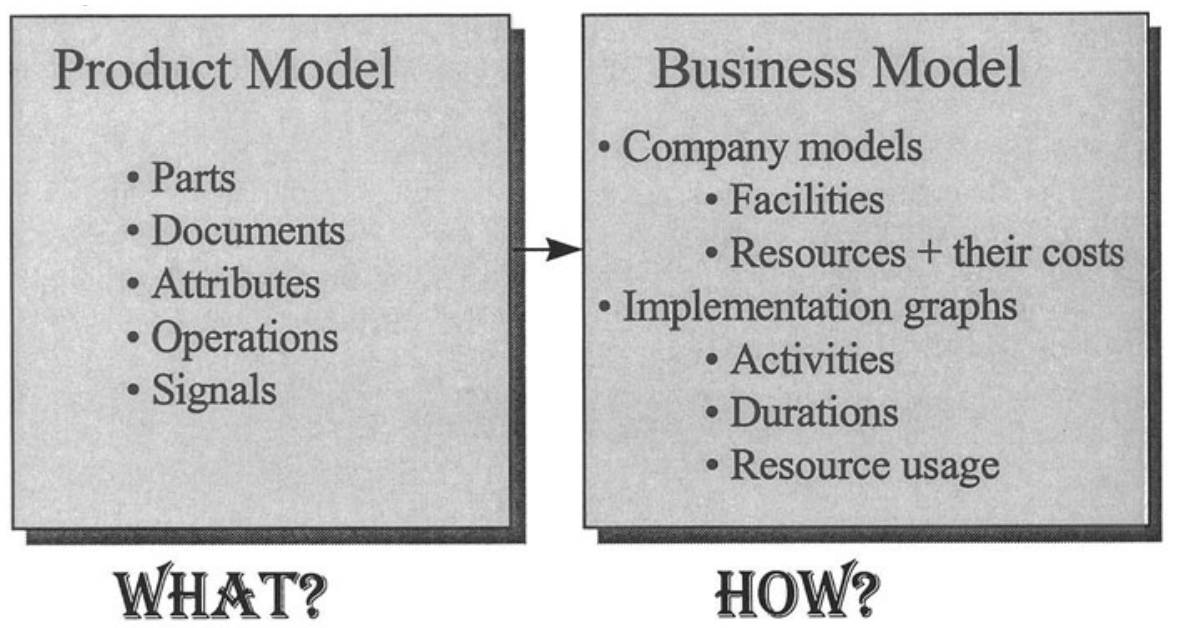

Figure 2 Modelling part of Simo-2 with MetaEdit+.

\subsection{Product Model}

A product model answers to the question 'what is produced?' It describes the structure of the final product e.g. power plant, paper machine, ship, construction etc. It includes parts and subparts in a hierarchical tree structure. For each part the following information is filled in:

- part name and documentation;

- operations;

- documents;

- attributes of documents;

- facilities;

- document links.

Operations are physical functions e.g. manufacturing, testing, erecting etc. that are needed for producing the part. The functions are modelled bottom-up i.e. the subparts are manufactured and the parts are assembled.

Documents are used for modelling document flow of a project i.e. design documents, schedules, manufacturing certificates etc. Design is modelled using documents instead of operations because the document flow goes top-down and so does the design function. Documents can be linked to real documents made using different softwares.

Attributes describe the most critical features included in a document. In a design document these could be e.g. pressure, temperature or mass flow. The attributes 
can also be used for describing the complexity of a certain function, customer, area etc.

Facilities can be e.g. departments of a company, factories or design offices. In a product model the user defines facilities that are able to perform operations or documents.

The common product model includes also signals that are used for modelling the information and cash flow between the companies. The companies can send or receive signals e.g. call for tenders, plans for tender, inspections or invoices.

As the goal is to examine alternative project structures, the product model is assumed to be the least variable component. Though, several options for product model have to be created to be able to refer to different project structures.

\subsection{Business Model}

A business model answers to the question 'how does a facility execute the operations and do the documents?' The models are private, containing company models and implementation graphs. The company model is done for each company. It describes the facilities the company has, resources available at each facility and the costs of each resource and the locations of the facilities. The activities needed to execute an operation or to do a document are described in implementation graphs. For each activity the minimum, normal and maximum duration as well as resource usage are entered.

\subsection{Project Model}

When product and business models are ready, companies participating the network can start the project modelling phase. They start by defining a plant type, location, project participants, effective and hand-over dates and signing the main contract as well as subcontracts. Each contract includes information about terms of delivery, terms of payment, price, deadline and scope of operations.

After contracting phase, the project schedule is created. A project model is sharpened by defining resource usage and transportation details. Simo-2 is a multiuser tool, and several users can cooperate during project planning phase, iterate the contract structure and change the schedule. Communication between the participants is done by a dedicated chat tool.

The simulation starts once every participant is ready with the models. From then on the simulator starts activating company-wise operations. During the simulation all data is gathered into a database for analysis. The data is transferred to MS Excel for analysing the results.

\section{CONCLUSIONS}

Simo-2 is a strategic information system for modelling and simulating the supply chain of project oriented companies. It uses information as a weapon for 
increasing the productivity, lowering costs and optimising processing time. The system is a state-of-the-art tool with new ideas of distributed business modelling and simulation. The system allows users to combine and compare alternative delivery structures. However, Simo-2 is more a communication than an optimisation tool. It brings the right employees from different companies to search for better ways of doing business together.

The contact persons of the companies are vital in the future development of the software. Only when they have thoroughly understood the modelling policy, do they have a chance to improve their business practices by simulating different strategic alternatives.

Simo-2 software can be used both on corporate and consortium level for finding new alternative ways to operate on a strategic level. It is extremely good for educational purposes inside the company because it clearly points out the most problematic situations in decision making when managing a large project. The tool includes a large, diversified glossary of terms used and of factors affecting decision making. It also includes e.g. example formats of the main contract and supplier contracts. Simo-2 can also be useful in marketing situations and in demonstrating project progress for potential customers.

The distributed use of Simo-2 supports the networking development and cooperation between the companies. The tool can be used for preliminary project planning and for comparing different delivery alternatives by all participants using a distributed computer network.

\section{REFERENCES}

BSCW Home Page. http://bscw.gmd.de

Jacobus WebSpace. http://www.jacobus.com

Jin, Y., Levitt, R. E., Christiansen, T. R., Kunz, J. C. (1995) The Virtual Design

Team: Modeling organizational behavior of concurrent design teams. Artificial Intelligence for Engineering Design, Analysis and Manufacturing (AI EDAM), Vol 9, 2, 1995.

Laurikkala, H. (1998) Virtual Plant Delivery Simulation - Efficiency by Networking. IX Internationales Produktionstechnisches Kolloquium PTK 98, 29.-30. October, 1998.

Laurikkala, H., Tanskanen, K., Nevalainen, P., Vainio-Mattila, M. (1999) Consortium as a Virtual Enterprise in Project Planning, 5th International Conference on Concurrent Enterprising, The Hague, The Netherlands, March 15-17, 1999.

MUSSELS Project Home Page. http://www.isasystems.de/cimweb/en/cim/projects/mussels/

Rose, T. (1998) Visual Assessment of Engineering Processes in Virtual Enterprises. Communications ACM Vol. $41 \mathrm{Nr}$ 12, 1998. 


\section{BIOGRAPHY}

M. Sc. Heli Laurikkala is a senior researcher at Tampere University of Technology in the Institute of Industrial Management. She graduated in 1993 and has worked in the field of logistics and information systems.

M. Sc. Eila Pajarre is a researcher at Tampere University of Technology in the Institute of Industrial Management. She graduated in 1997 and has worked in the field of information systems. 